\title{
5,7-Dihydroxy-2-(4-hydroxyphenyl)chroman-4-one Functionalized CuO Nanoparticles: Synthesis, Characterization and Antioxidant Activity
}

\author{
Qadeer Khan Panhwar ${ }^{*}$, Aamna Balouch ${ }^{2}$, Ali Nawaz Siyal ${ }^{1}$, Farida Shaikh ${ }^{1}$, \\ Sanaullah Dehraj ${ }^{3}$, Wazir Ali Panhwar ${ }^{4}$ and Aqsa Ahmed ${ }^{5}$ \\ ${ }^{1}$ Dr. M. A. Kazi, Institute of Chemistry, University of Sindh, Jamshoro 76080, Pakistan. \\ ${ }^{2}$ National Center of Excellence in Analytical Chemistry, University of Sindh, Jamshoro 76080, Pakistan. \\ ${ }^{3}$ Dpartment of Basic Science and Related Studies, Quaid-E-Awam University of Engineering, Science and \\ Technology 67480, Nawab Shah, Pakistan. \\ ${ }^{4}$ Institute of Physic, University of Sindh, Jamshoro 76080, Pakistan. \\ ${ }^{5}$ Department of Chemistry, University of Engineering and Technology, Lahore 54890, Pakistan. \\ *Corresponding Author Email: qadeer.panhwar@usindh.edu.pk \\ Received 01 October 2019, Revised 05 April 2020, Accepted 21 May 2020
}

\begin{abstract}
Naringenin $(\mathrm{NaR})$ is a flavonoid, mostly found in citrus fruit. Its IUPAC name is 5,7-Dihydroxy2-(4-hydroxyphenyl)chroman-4-one. Naringenin is lipophilic in nature and possessing antioxidant property. In present study,7-Dihydroxy-2-(4-hydroxyphenyl)chroman-4-one was incorporated onto $\mathrm{CuO}$ nanoparticles $(\mathrm{CuO}-\mathrm{NPs})$ for enhancing its antioxidant activity. The $\mathrm{CuO}-\mathrm{NPs}$ and its functionalized form (CuO-NaR) were characterized by Fourier-transform infrared (FT-IR) spectroscopy, X-ray diffraction (XRD), Scanning electron microscope (SEM) and Energy dispersive X-ray (EDX) analysis. The CuO-NPs, CuO-NaR and $\mathrm{NaR}$ were examined for their comparative antioxidant activities followed by DPPH (2,2-Diphenyl-1-picrylhydrazyl) method. The results revealed that the antioxidant activity of $\mathrm{CuO}-\mathrm{NaR}$ was enhanced significantly.
\end{abstract}

Keywords: $\mathrm{CuO}$ nanoparticles, Naringenin, Antioxidant activity, DPPH

\section{Introduction}

Any material possessing at least one dimension $<100 \mathrm{~nm}$ is called nanomaterial [1]. The properties (physical and chemical) of nanomaterials are strongly depending on their compositions, size, shape and structure [2]. The shape of nanomaterial depends on the length of three dimensions. Based on the dimensions, the nanomaterials are classified as zero-dimension (0D), one-dimension (1D), twodimension (2D) and three-dimension (3D) materials. In OD material, three dimensions are in nano range and materials can be nanoparticles and quantum dots. In 1D material, one dimension is out of the nano range, while two dimensions are in nano range and material can be nanorods, nanotubes and nanowires. In 2D material, two dimensions are out of the nano range, while one dimension is in nano range and material can be nanofilms, nanolayers and nanocoatings. In 3D material, all the dimensions are out of the nano range and material can be core shells, multi nanolayers, bundles of nanowires, bundles of nanotubes $[3,4]$. The nanomaterials with unique properties can be synthesized by modifying their size and shape [5-9]. Based on their constituents, size, morphology and properties, the nanomaterials are classified as carbon-based nanomaterials, metal based nanomaterials, semiconductor nanomaterials, lipid-based nanomaterials and polymeric nanomaterials [10]. Different methods such as laser ablation [11], 
electron beam irradiation [12], in-situ chemical synthetic route [13] include thermal decomposition [14] and chemical reduction [15] have been employed for the preparation of metal based nanoparticles. Chemical reduction method is the most attractive because of simple and cost effective and size of the material can be vary by optimizing experimental factors such as precursor salt, solvent, capping agent, reducing agent, solvent, reaction time, and temperature $[16,17]$. The nanomaterial can be tailored by functionalization strategies [18]. This study will focus on the synthesis of $\mathrm{CuO}$ NPs and its functionalization with antioxidant moieties for enhancing its activity.

\section{Materials and Methods Materials}

Analytical reagent-grade chemicals and double distilled water (18.2 $\mathrm{M}$ ohm $\mathrm{cm}$ ) were used throughout experimental work. $\mathrm{CuSO}_{4} \cdot 5 \mathrm{H}_{2} \mathrm{O}$, $\mathrm{NaOH}, \quad \mathrm{H}_{2} \mathrm{SO}_{4}, \quad \mathrm{KH}_{2} \mathrm{PO}_{4}, \quad \mathrm{~K}_{2} \mathrm{HPO}_{4} \quad$ and Dichloroacetic acid $\left(\mathrm{Cl}_{2} \mathrm{CHCOOH}\right)$, Sodium dodecyl sulfate (SDS), L- Ascorbic acid and Naringenin (NaR) were purchased from Merck, Germany. FT-IR Spectrometer (Thermo Scientific, Nicolet iS10, UK) was used for recording FT-IR spectra. Bruker X-Flash 4010 133ev (made in Germany) using $\mathrm{Cu} \mathrm{K \alpha}(1=1.5406 \AA$ ) radiation was used for EDX analysis.

\section{Synthesis of $\mathrm{CuO} \mathrm{NPs}$}

CuO-NPs were synthesized by chemical reduction method [16] using $\mathrm{CuSO}_{4} .5 \mathrm{H}_{2} \mathrm{O}$ as precursor salt and SDS as a capping agent. Experimentally, $1.0 \mathrm{~mL}$ of SDS solution $(1.0 \mathrm{M})$ was added to $20 \mathrm{~mL}$ of $0.1 \mathrm{M} \mathrm{CuSO} 4.5 \mathrm{H}_{2} \mathrm{O}$ solution and stirred vigorously for $30 \mathrm{~min}$ and 50 $\mathrm{mL}$ of $0.2 \mathrm{M} \mathrm{L}$-Ascorbic acid solution was added with continuous stirring. Furthermore, $30 \mathrm{~mL}$ of $1.0 \mathrm{M} \mathrm{NaOH}$ solution was slowly added to the mixture with constant stirring and heated at $80{ }^{\circ} \mathrm{C}$ for $2 \mathrm{~h}$. For work-up of the reaction, the mixture was settled overnight at room temperature, and the supernatant solution was discarded and filtered. The precipitates were washed subsequently with water and ethanol for three times and dried at room temperature. The precipitates were calcined by heating in furnace at $300{ }^{\circ} \mathrm{C}$ for $3 \mathrm{~h}$ for complete conversion of $\mathrm{Cu}(\mathrm{OH})_{2}$ into $\mathrm{CuO}$ NPs.

\section{Functionalization of NaR onto the surface of $\mathrm{CuO} \mathrm{NPS}$}

For functionalization of $\mathrm{CuO}$ NPs, 0.01 $\mathrm{mg}$ of $\mathrm{CuO} \mathrm{NP}$ was dispersed in $20 \mathrm{~mL}$ of methanol and $100 \mathrm{mg}$ of $\mathrm{NaR}$ was added with stirring at room temperature for $1 \mathrm{~h}$. The reaction mixture was settled for overnight and the supernatant solution was discarded and filtered. The product was washed with methanol for several times to remove unreacted $\mathrm{NaR}$. The final product (CuO-NaR) was dried by evaporating the methanol at room temperature.

\section{Antioxidant activity}

The free radical scavenging activities (FRSA) of $\mathrm{CuO} \mathrm{NPs}, \mathrm{CuO}-\mathrm{NaR}$ and $\mathrm{NaR}$ were tested followed by DPPH method [19, 20]. In a typical procedure, $0.2 \mathrm{mg}$ of $\mathrm{CuO}-\mathrm{NPs}$ was dispersed in $3.20 \mathrm{~mL}$ of $100 \mu \mathrm{M}$ DPPH solution (prepared in methanol). The concentration of free radical was monitored after each of $0,2,4,6,8$, $10,12,14$ and 16 min followed by absorbance recording at $\lambda_{\max }$ of $517 \mathrm{~nm}$. The free radical scavenging activities of $\mathrm{NaR}$ and $\mathrm{CuO}-\mathrm{NaR}$ were also tested followed by the same procedure. FRSA (decolourization) of $\mathrm{CuO}$ NPs, $\mathrm{CuO}-\mathrm{NaR}, \mathrm{NaR}$ were calculated by equation 1 .

Decolourization $(\%)=\left[1-\left(\right.\right.$ Absorbance $_{(\text {sample })} /$
Absorbance $\left.\left._{(\text {control) })}\right)\right] \times 100$

\section{Ferric reducing antioxidant potential (FRAP)}

FRAP study of $\mathrm{CuO}$ NPs, CuO-NaR and $\mathrm{NaR}$ was carried out by reported method [21]. Experimentally, the series of test solutions 0.5-3.0 $\mathrm{mg} / \mathrm{mL}$ of $\mathrm{CuO}$ NPs were prepared. For testing FRAP, $0.5 \mathrm{~mL}$ of test solution was taken into small glass tube and $2.5 \mathrm{~mL}$ of $\mathrm{KH}_{2} \mathrm{PO}_{4} / \mathrm{K}_{2} \mathrm{HPO}_{4}$ buffer solutions was mixed to the solution for maintaining $\mathrm{pH}$ 7.5. Therefater, $2.5 \mathrm{~mL}$ of $1.0 \%$ (w/v) $\mathrm{K}_{3}\left[\mathrm{Fe}(\mathrm{CN})_{6}\right]$ (potassium ferricyanide) was mixed to the solution and incubated at $25^{\circ} \mathrm{C}$ for $20 \mathrm{~min}$. Then $2.5 \mathrm{~mL}$ of $10 \%$ (w/v) dichloroacetic acid was mixed in it and centrifuged at $3000 \mathrm{rpm}$ 
for $10 \mathrm{~min}$. Then $2.5 \mathrm{~mL}$ from upper layer (supernatant) of solution was transferred to another small glass tube containing $2.5 \mathrm{~mL}$ of water and $0.5 \mathrm{~mL}$ of $0.1 \%(\mathrm{w} / \mathrm{v})$ ferric chloride solution and placed in dark for $15 \mathrm{~min}$. Then solution was subjected to spectrophotometer at $\lambda_{\max }$ of $700 \mathrm{~nm}$ for absorbance recording against blank. Same procedure was applied for testing FRAP of NaR and $\mathrm{CuO}-\mathrm{NaR}$.

\section{Total antioxidant capacity (TAC)}

TAC of $\mathrm{CuO}$ NPs, CuO-NaR and $\mathrm{NaR}$ was evaluated separately by reported procedure [22]. Experimentally, $1.0 \mathrm{~mL}$ of alcohol containing $0.5 \mathrm{mg}$ of $\mathrm{CuO}-\mathrm{NPs}$ was taken in a glass tube containg $0.5 \mathrm{~mL}$ reagent solution $(0.6 \mathrm{M}$ $\mathrm{H}_{2} \mathrm{SO}_{4}, 28 \mathrm{mM}$ sodium phosphate and $4 \mathrm{mM}$ ammonium molybdate) and incubated at $95{ }^{\circ} \mathrm{C}$ for $150 \mathrm{~min}$. The content was cooled at room temperature and subjected to spectrophotometer at $\lambda_{\max }$ of $595 \mathrm{~nm}$ for absorbance recording against blank at different intervals of times i.e. 20, 40, 60, 80,100 and $120 \mathrm{~min}$. Same procedure was applied for testing TAC of $\mathrm{NaR}$ and $\mathrm{CuO}-\mathrm{NaR}$.

\section{Results and Discussion FT-IR spectroscopy}

The Fig. 1 shows FT-IR spectra of $\mathrm{CuO}$ NaR. The characteristic peaks at 3269.32, $1614.01,15.60 .22$ and $1049.68 \mathrm{~cm}^{-1}$ correspond to the stretching vibrations of $\mathrm{O}-\mathrm{H}, \mathrm{C}=\mathrm{O}, \mathrm{C}=\mathrm{C}$ and $\mathrm{C}-\mathrm{O}$ bonds, respectively of $\mathrm{NaR}$. The peaks at 795.54 and $650.91 \mathrm{~cm}^{-1}$ correspond to stretching vibrations of $\mathrm{Cu}-\mathrm{O}$ bond [23]. This spectral information revealed the successful incorporation of $\mathrm{NaR}$ onto the surface of $\mathrm{CuO}$ NPs.

\section{X-ray diffraction (XRD)}

The Fig. 2 depicts the XRD pattern of CuO-NPs. The diffraction peaks at $2 \theta=31.058^{\circ}$, $35.703^{\circ}, 38.932^{\circ}, 48.877^{\circ}, 53.831^{\circ}$ and $56.352^{\circ}$ correspond tp (110), (002), (111), (-202), (020) and (202) planes of monoclinic phase of $\mathrm{CuO}-\mathrm{NPs}$ respectively, which confirmed the formation of CuO-NPs phase [24]. According to Bragg's law (d $=n \lambda / 2 \operatorname{Sin} \theta$, where $\lambda$ is wave length of $X$-rays (for $\mathrm{Cu} \mathrm{K} \alpha, \lambda=1.54056 \AA$ ) and $\mathrm{n}=1$ (order of diffraction) and $\theta$ is position of peaks in radian) [24]. The Basal spacing of (002) and (111) planes was calculated and found to be 0.25 and $0.23 \mathrm{~nm}$, respectively. According to Debye Scherrer equation [25], the average crystallite size of $\mathrm{CuO}$ NPs was calculated and found to be $16.40 \mathrm{~nm}$.

\section{Scanning electron microscope (SEM)}

$\mathrm{CuO}-\mathrm{NPs}$ and $\mathrm{CuO}-\mathrm{NaR}$ were characterized by SEM at different resolutions as shown in Fig.3a-f. The SEM images a-c evidently discovered the morphology of the $\mathrm{CuO}-\mathrm{NP}$ as spherical in shape, clustered and porous. After the functionalization of CuO-NPs, the morphology of nanoparticles was changed to crystalline and smooth as shown in images $d-f$, which indicated that $\mathrm{NaR}$ smoothen the surface of nanoparticles and acted as capping agent to prevent agglomeration and functionalized the $\mathrm{CuO}-\mathrm{NPs}$.

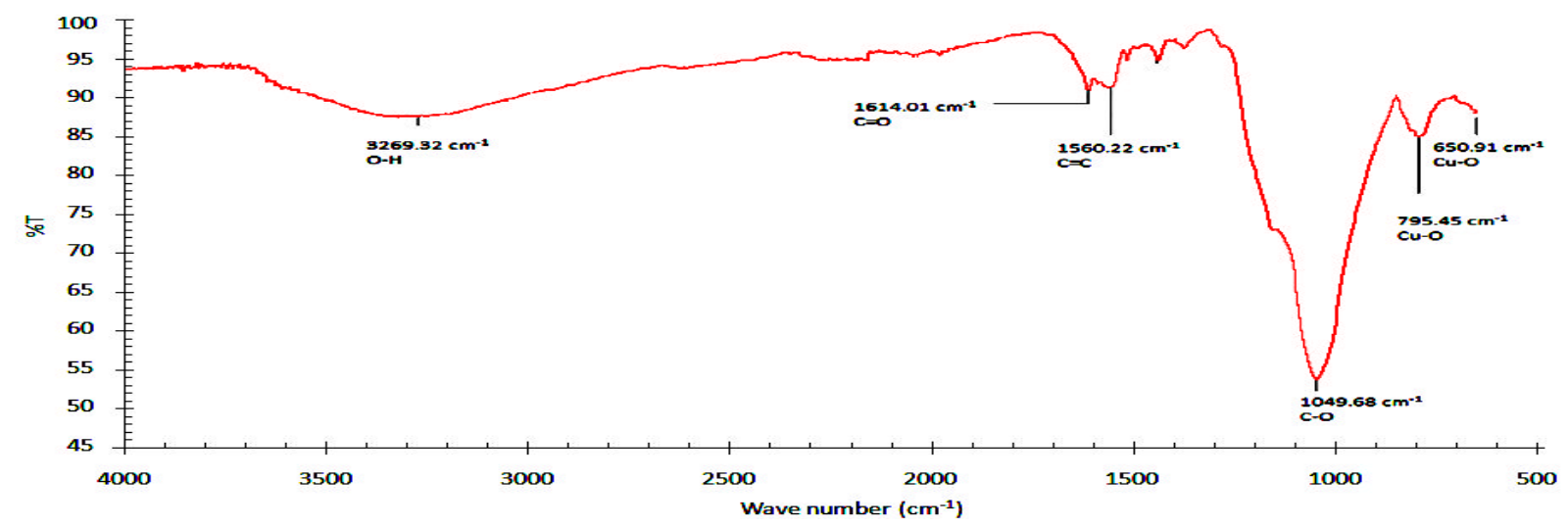

Figure 1. FT-IR Spectrum of CuO-NaR 


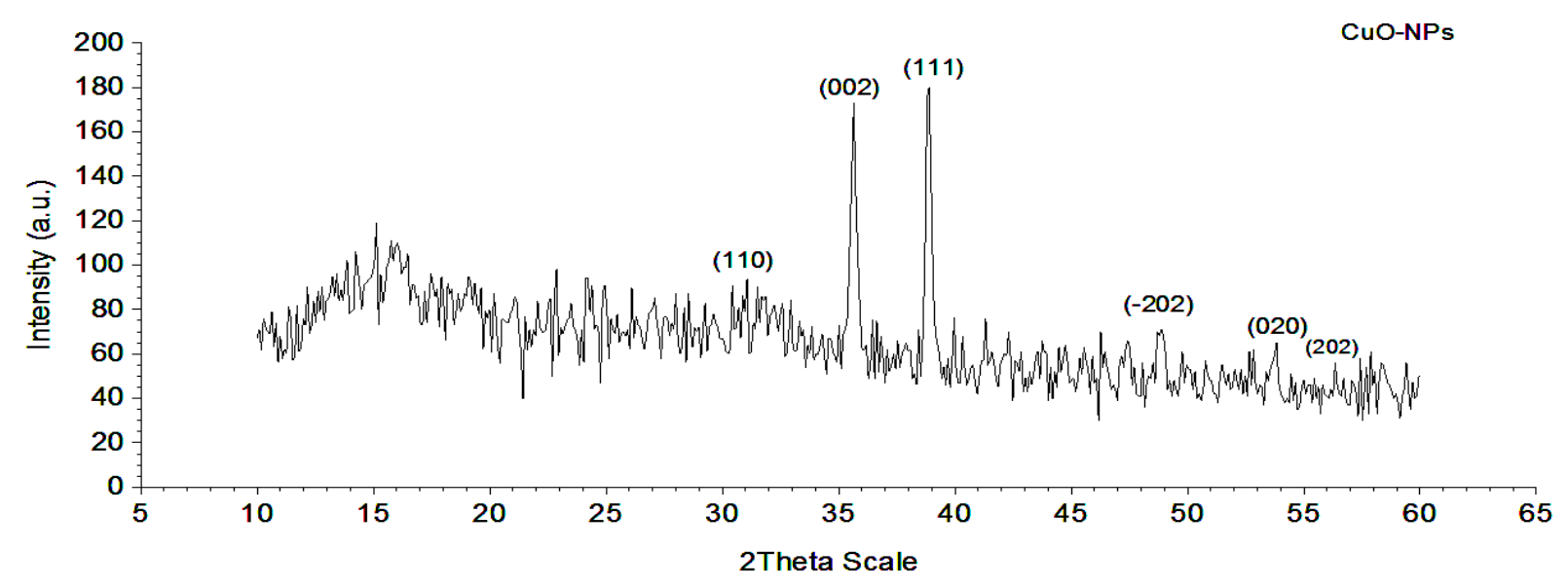

Figure 2. EDX pattern of $\mathrm{CuO}-\mathrm{NPs}$
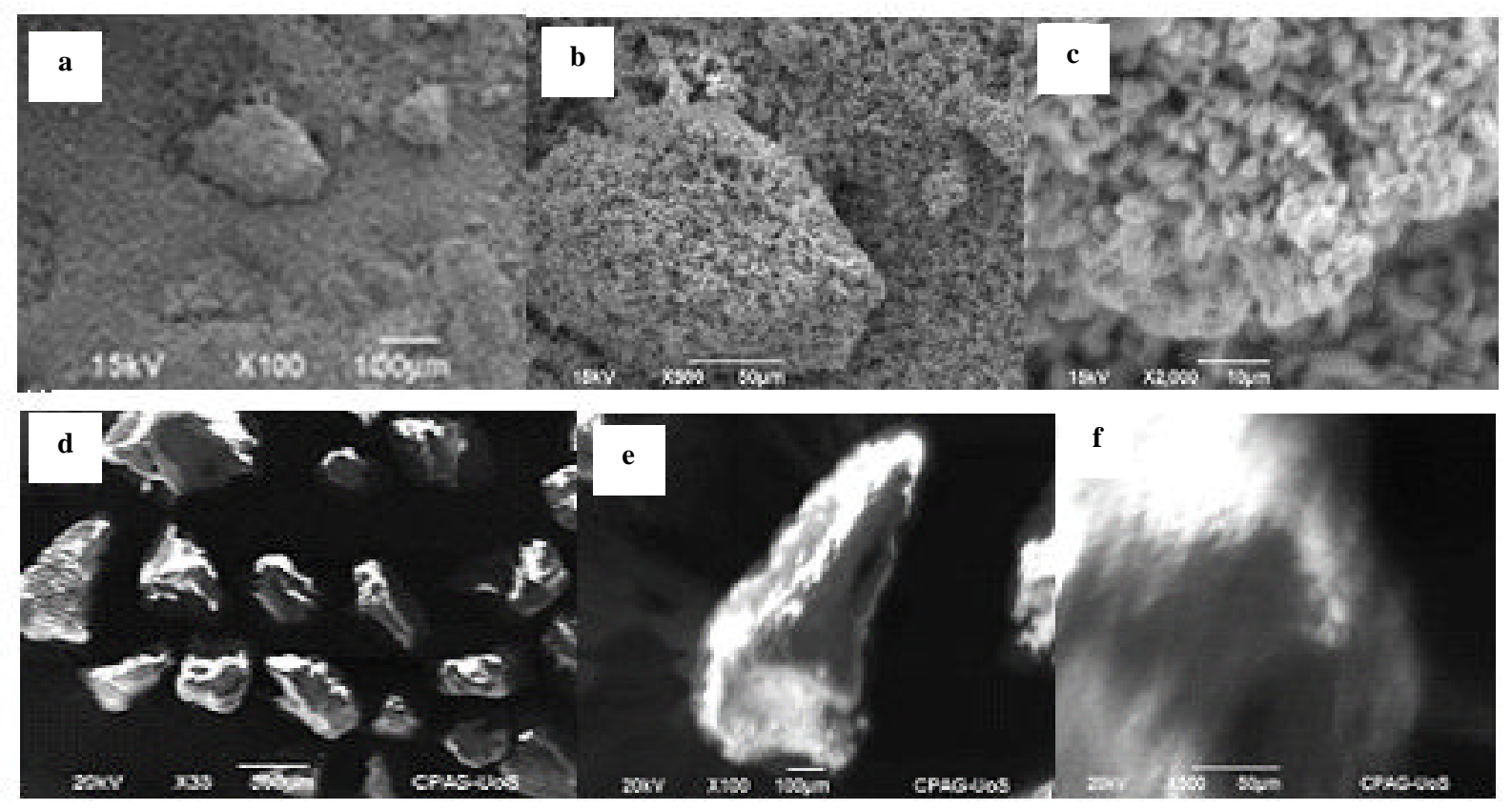

Figure 3. SEM Images of CuO NPs (a-c) and CuO-NaR-NPs (d-f) at different resolutions

\section{Energy dispersive X-ray (EDX)}

CuO-NPs and $\mathrm{CuO}-\mathrm{NaR}$ were characterized by EDX analysis for elemental quantification. For analysis, the electron-beam was bombarded onto the surface of sample, which caused the generation of K $\alpha$ x-rays. The energy of $\mathrm{x}$-rays is the characteristic of elements present in the sample. EDX (Fig. 4a) of CuO NPs depicts that the contents of $\mathrm{Cu}: 75.06 \%, \mathrm{C}: 4.72 \%$ and $\mathrm{O}$ :
$18.6 \%$, in CuO-NPs are closely related to the theoretical contents of $\mathrm{Cu}: 79.89 \%$ and O: $20.11 \%$ in $\mathrm{CuO}$, confirmed the formation of $\mathrm{CuO}$ phase. While EDX (Fig. 4b) of CuO-NaR shows the contents of $\mathrm{Cu}: 28.83 \%, \mathrm{C}: 28.83 \%$ and $\mathrm{O}$ : $46.18 \%$ in $\mathrm{CuO}-\mathrm{NaR}$. The increased in contents of $\mathrm{C}$ and $\mathrm{O}$ elements in $\mathrm{CuO}-\mathrm{NaR}$, indicated the successful incorporation of $\mathrm{NaR}$ onto the $\mathrm{CuO}$ NPs. 


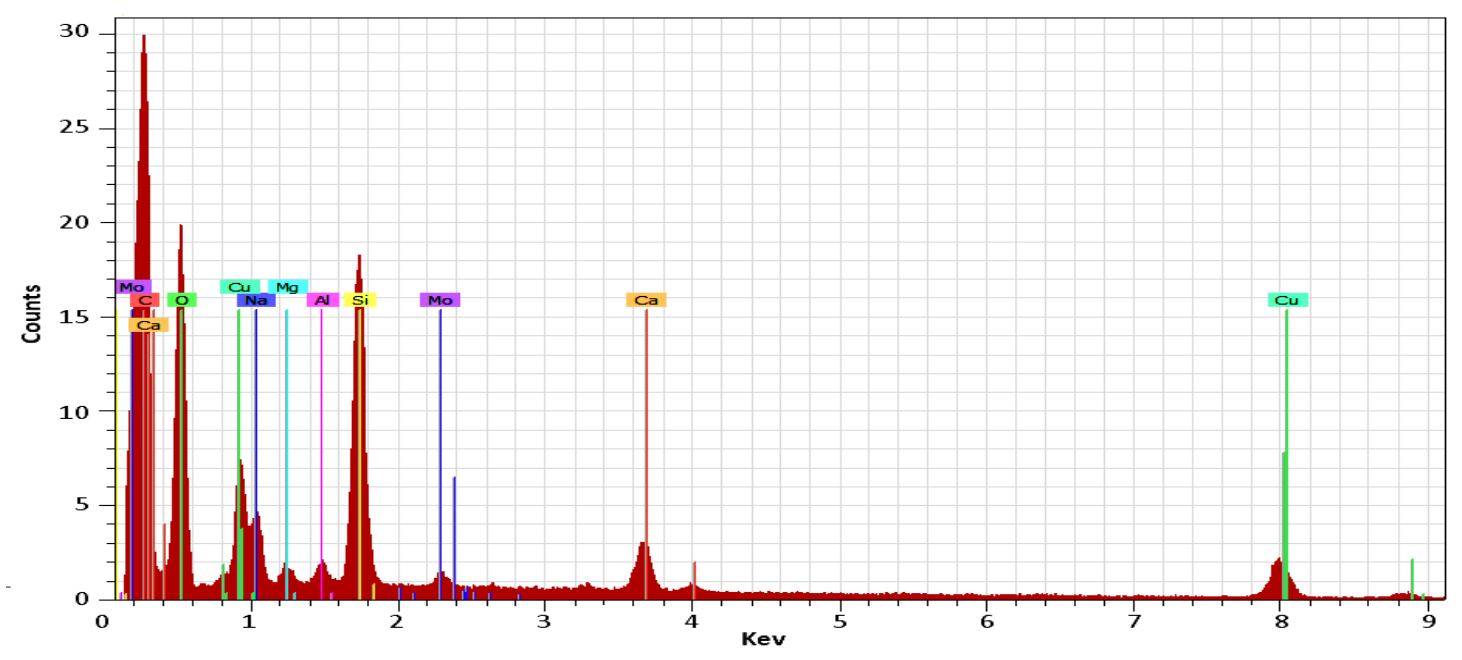

Figure 4(a). EDX of CuO-NPs

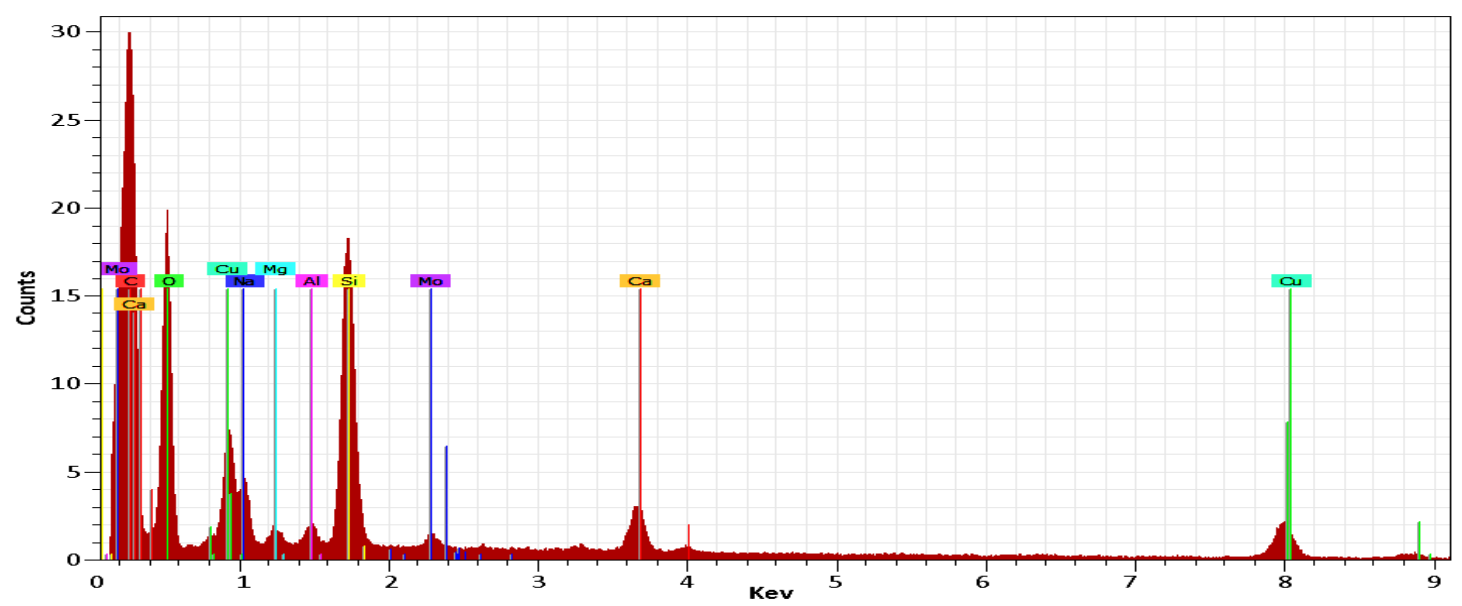

Figure 4(b). EDX of CuO-NaR

\section{DPPH radical scavenging}

DPPH was used as source of free radical while $\mathrm{CuO}$ NPs and $\mathrm{CuO}-\mathrm{NaR}$ were acted as free radical scavenger. Fig. 5 shows comparative FRSA of CuO-NPs, NaR and CuO-NaR. The results revealed that $\mathrm{CuO}-\mathrm{NaR}$ possessed greater FRSA than $\mathrm{CuO}-\mathrm{NP}$ and $\mathrm{NaR}$

\section{Ferric reducing antioxidant potential (FRAP)}

FRAP study of $\mathrm{CuO}, \mathrm{NaR}$ and $\mathrm{CuO}-\mathrm{NaR}$ $\mathrm{NP}$ was carried out in the concentration range of 0.5-3.0 $\mathrm{mg} / \mathrm{mL}$. In this method, iron in ferricyanide complex is $\mathrm{Fe}^{3+}$, which was reduced to $\mathrm{Fe}^{2+}$ by gaining electron from antioxidants [24].
Fig. 6 depicted that with FRAP was increased with increasing of antioxidants. FRAP of $\mathrm{CuO}-\mathrm{NaR}$ was greater that $\mathrm{CuO}-\mathrm{NPs}$ and $\mathrm{NaR}$ at all the levels of concentration.

\section{Total antioxidant capacity (TAC)}

TAC of CuO-NPs, CuO-NaR and NaR were evaluated. Fig. 7 depicts that after the 20 min, absorbance of content was not enhanced significantly. The $\mathrm{CuO}-\mathrm{NaR}$ based content has greater absorbance value tham CuO-NPs and $\mathrm{NaR}$. Therefore, $\mathrm{CuO}-\mathrm{NaR}$ possessed comparatively greater TAC. 


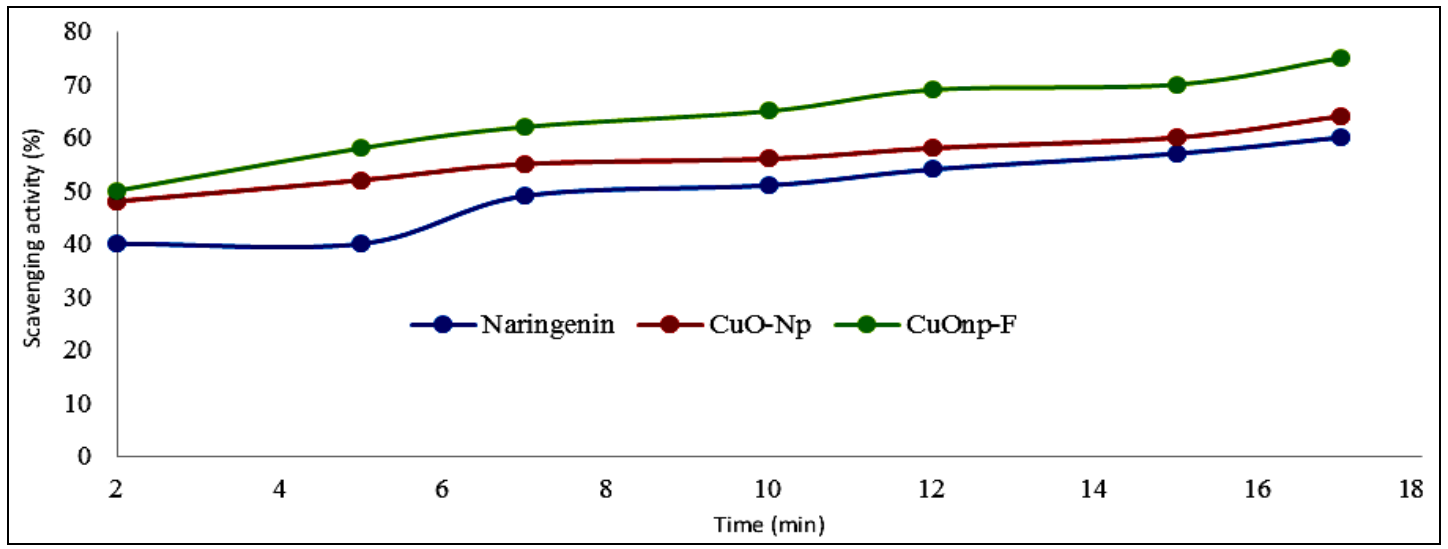

Figure 5. FRSA of CuO NPs, CuO-NaR and NaR

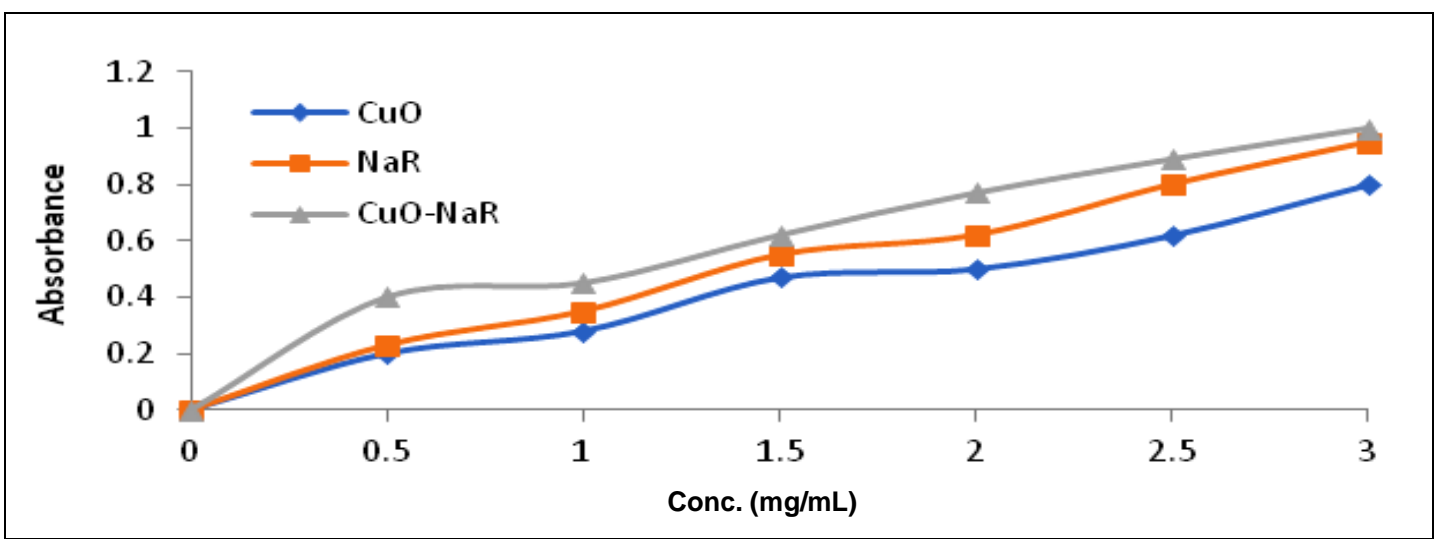

Figure 6. FRAP of CuO NPs, CuO-NaR and NaR

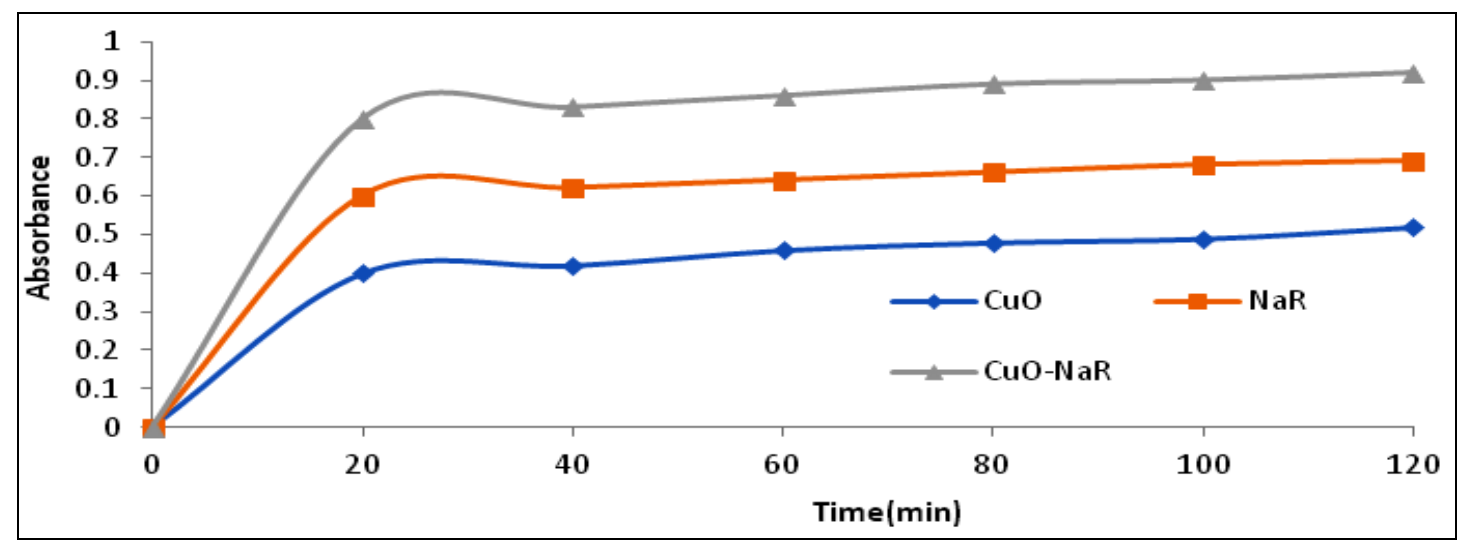

Figure 7. TAC of CuO NPs, CuO-NaR and NaR 


\section{Conclusion}

$\mathrm{CuO}$ nanoparticles (CuO-NPs) were synthesized by chemical reduction method using $\mathrm{CuSO}_{4} .5 \mathrm{H}_{2} \mathrm{O}$ as precursor salt and sodium SDS as a capping agent. The formation of monoclinic phase of CuO-NPs was confirmed by X-ray powder diffraction and the average crystallite size was found to be $16.40 \mathrm{~nm}$. The morphology of the $\mathrm{CuO}-\mathrm{NPs}$ was spherical in shape, clustered and porous. CuO-NPs were functionalized with $\mathrm{NaR}$. The characteristic peaks in FT-IR spectrum at $3269.32,1614.01,15.60 .22$ and $1049.68 \mathrm{~cm}^{-1}$ corresponded to the stretching vibrations of $\mathrm{O}-\mathrm{H}$, $\mathrm{C}=\mathrm{O}, \mathrm{C}=\mathrm{C}$ and $\mathrm{C}-\mathrm{O}$ bonds, respectively of $\mathrm{NaR}$. The peaks 795.54 and $650.91 \mathrm{~cm}^{-1}$ are associated with vibration of to the $\mathrm{C}-\mathrm{O}$ bond. This spectral information revealed the successful incorporation of $\mathrm{NaR}$ onto the surface of CuO-NPs. Antioxidant activity of $\mathrm{NaR}$ was enhanced significantly by functionalization with CuO-NPs. The mechanism of antioxidant activity may be in dose-dependent manner. It can also be fulfilled by free radical reduction, depending on the structure of metal oxide as well as structure of adduct of functionalized $\mathrm{CuO}-\mathrm{NaR}$.

\section{References}

1. M. H. Islam, M. T. Y. Paul, O. S. Burheim and B. G. Pollet, Ultrason. Sonochem., 59. (2019) 104711. doi.org/10.1016/j.ultsonch.2019.104711.

2. Q. Zhang, K. Zhang, D. Xu, G. Yang, H. Huang, F. Nie, C. Liu and S. Yang, Prog. Mater. Sci., 60 (2014) 337. doi: org/10.1016/j.pmatsci.2013.09.003

3. D. Vollath, Nanomaterials: An Introduction to Synthesis, Properties and Applications (Wiley-VCH) 2/ed. (2019).

4. J. N. Tiwari, R. N. Tiwari and K. S. Kim, Prog. Mater. Sci., 57 (2012) 724. doi: org/10.1016/j.pmatsci.2011.08.003.

5. C. D. Sai, M. Q. Luu, V. V. Le, P. M. Nguyen, N. H. Pham, V. T. Nguyen, X. Q. Nguyen, Q. K. Doan and T. H. Tran, J. Electron. Mater., 46 (2017) 3674. doi:10.1007/s11664-016-5278-7.
6. Q. K. Doan, M. H. Nguyen, C. D. Sai, V. T. Pham, H. H. Mai, N. H. Pham, T. C. Bach, V. T. Nguyen, T. T. Nguyen, K. H. Ho and T. H. Tran, Appl. Surf. Sci., 505 (2020) 144. doi.org/10.1016/j.apsusc.2019.144593.

7. L. M. Quynh, N. T. Tien, P. V. Thanh, N. M. Hieu, C. D. Sai, N. T. Thuat, N. V. Tuyen, N. H. Luong and N. L. H. Hoang, Physica B Condens. Matter, 532 (2018) 200. doi:10.1016/j.physb.2017.05.024.

8. N. V. Tuyen, N. N. Long, T. T. Q. Hoa, N. X. Nghia, D. H. Chi, K. Higashimine, T. Mitani and T.D. Canh, J. Exp. Nanosci., 4 (2009) 243. doi:10.1080/17458080802627482.

9. T. H. Tran, T. T. A. Tang, N. H. Pham, T. C. Bach, C. D. Sai , Q. H. Nguyen, V. V. Le, H. N. Nguyen, Q. K. Doan, T. T. Nguyen, V. B. Le, K. H. Ho and V. T. Nguyen, $J$. Chem., 8 (2019). doi:10.1155/2019/3568185.

10. L. A. Kolahalam, I. V. K. Viswanath, B. S. Diwakar, B. Govindh, V. Reddy and Y. L. N. Murthy, Mater. Today: Proc., 18 (2019) 2182.

doi: org/10.1016/j.matpr.2019.07.371.

11. R. M. Tilaki, A. Irajizad and S. M. Mahdavi, Appl. Phys. A, 88 (2007) 415. doi: 10.1007/s00339-007-4000-2.

12. R. Zhou, X. Wua, X. Hao, F. Zhou, H. Li and W. Rao, Nucl. Instrum. Meth. Phys. Res. B, 266 (2008) 599. doi:org/10.1016/j.nimb.2007.11.040.

13. K. Mallick, M. J. Witcomb and M. S. Scurrell, Eur. Polym. J., 42 (2006) 670. doi: org/10.1088/0953-8984/19/19/196225

14. M. S. Niasari and F. Davar, Mater. Lett., 63 (2009) 441.

doi: 10.1007/s10971-009-1940-3

15. W. Yu, H. Xie, L. Chen, Y. Li and C. Zhang, Nanoscale Res. Lett., 4 (2009) 465. doi: 10.1007/s11671-009-9264-3.

16. T. M. D. Dang, T. T. L. T. Tuyet, E. Fribourg-Blanc and M. C. Dang, Adv. Nat. 
Sci. Nanosci. Nanotechnol., 2 (2011) 6. doi:10.1088/2043-6262/2/1/015009.

17. T. H. Trana, T. C. Bachb, N. H. Phamb, Q. H. Nguyenb, C. D. Saib, H. N. Nguyenb, V. T. Nguyenb, T. T. Nguyenc, K. H. Hod and Q. K. Doan, Mater. Sci. Semicond Process., 89 (2019) 125. doi:10.1016/j.mssp.2018.09.002.

18. M. Faraz, M. Z. Ansari and N. Khare, Mater. Chem. Phys., 211 (2018) 143. doi:10.1016/j.matchemphys.2018.02.011.

19. D. Das, B. C. Nath, P. Phukon and S. K. Dolui, Colloid. Surf. B, 101 (2013) 433. doi:10.1016/j.colsurfb.2012.07.002.

20. W. Brand-Williams, M. E. Cuvelier and C. Berset, LWT-Food Sci. Technol., 28 (1995) 30. doi:10.1016/s0023-6438(95)80008-5.
21. M. Oyaizu, J. Nutr. Diet., 44 (1986) 315. doi: 10.5264/eiyogakuzashi.44.307.

22. P. Prieto, M. Pineda and M. Aguilar, Anal. Biochem., 269 (1999) 341. doi:10.1006/abio.1999.4019.

23. A. Goswami, P. K. Raul and M. K. Purkait, Chem. Eng. Res. Des., 90 (2012) 1396. doi:10.1016/j.cherd.2011.12.006.

24. N. Tamaekong, C. Liewhiran and S. Phanichphant, J. Nanomater., (2014) 2014, 5. doi:10.1155/2014/507978.

25. F. P. Fato, L. Da-Wei, Z. Li-Jun, Q. Kaipei, and L. Yi-Tao, ACS Omega, 4 (2019) 7543. doi:10.1021/acsomega.9b00731 